\title{
EDUCACION Y FILOSOFIA
}

\section{Estanislao Zuleta}

Vamos a hablar esta noche del tema de la Educación y la Filosofía. Voy a tomar el problema de una manera bastante simplificada y, por decirlo así, polarizada, llevándolo a dos consideraciones muy extremadas -pero no extremistas-sobre el tema de la Educación.

La primera consideración es un enfoque de la Educación como proceso de formación, de acceso al pensamiento en el sentido más clásico y en el sentido en que la filosofía lo consideró des de la antigüedad.

La segunda es la consideración de la Educación como un sistema de producción de fuerza de trabajo calificada, para una demanda que existe en el mercado.

En cierto modo, en uno u otro período histórico, la educación tiende a ser una cosa más que la otra. $\mathrm{O}$ un procedimiento de simple transmisión de un saber ya adquirido, cuando no se trata de la producción directa para el mercado, o un procedimiento de formación en el sentido de acceso al pensamiento y el saber. $Y$ más o menos combinaciones.

El primer enfoque de la Educación, fundamentalmente como formación, es el enfoque platónico y más tarde el enfoque racionalista -Descartes, Spinoza, Kant-, en el cual lo que se trata de saber es cuáles son las condiciones efectivas para el acceso al conocimiento. Probablemente la línea de anális is de la educación en este sentido, la búsqueda de responder (en ese sentido) a la pregunta: ¿Qué significa enseñar?, el enfoque más puro, digámoslo así, es el de Platón -y sus sucesores que son innumerables- que se podría resumir así: lo importante para Platón es combatir la ignorancia. Digámoslo en sus téminos, tal como lo expone en El Sofista: el problema fundamental de la educación es combatir la ignorancia. El (Platón) considera que la educación no es un problema similar al de dar de comer a un hambriento, pues en ese caso el asunto seria muy sencillo. El verdadero problema es hacer salir a alguien de una indigestión para que pueda tener apetito. Porque lo que impide el acceso al saber, lo que Platón llama la ignorancia, no es una carencia, es, por el contrario, un exceso de opiniones en las que tenemos una confianza loca. El prejuicio, como lo llamarán Descartes, Spinoza o Kant, y que Platón llamaba la opinión, está siempre ya allí. El prejuicio es, por decirlo así, el punto de partida.

Por ejemplo, mientras más atrasado está un grupo humano, en cierto modo, mayor es el número de sus prejuicios y de sus opiniones, Si está, digámoslo en

\footnotetext{
“ Conferencia del Profesor Estanislao Zuleta. Facultad de Ciencias de la Educación. Universidad Libre. Bogotá. 21 y 22 de noviembre de 1978.
} 
términos nuestros, en un período en el que el pensamiento es mágico, podrá dar cuenta de todo lo que ocurre, de eclipses o de las mareas o de cualquier fenómeno orgánico, de las enfermedades y de las curaciones, todo dentro de un sistema mágico.

A contrario, sería ya un gran avance que llegara a saber que hay algo que no sabe. Los conocimientos científicos nos pemiten deteminar claramente nuestro saber; para un médico es muy fácil decir que no conocemos el origen del cáncer pero a un chamán no se le ocurriría saber que hay algo que no conoce.

Lo primero, pues, es establecer una crítica de la opinión. Muchas veces se ha hecho en la historia ese proceso.

Ustedes recuerdan que Sócrates continuamente iba diciendo aquella frase maliciosa "sólo sé que nada sé". Maliciosa, porque está muy lejos de ser falsa modestia; eso, en el contexto de Platón, es ya un saber muy alto y sólo puede ser el resultado de una elaboración muy avanzada, lo que lo conduce a uno a un no saber. Detrás de eso, tiene que haber ya una crítica de lo que creía saber, que no era más que una opinión.

Ese mismo camino se logra encontrar, por ejemplo, en Descartes con su duda metódica, cuando se encuentra cómo sometió a la duda todo el aprendizaje del Colegio de las Leyes en donde estudió, y decidió cerrar todos los libros aprendidos y abrir el gran libro del mundo.

La idea de Platón es, pues, que la educación efectiva tiene que comenzar por crear una necesidad de saber, por medio de la crítica de la opinión.

En segundo lugar, esa necesidad de saber no es pensada por Platón como una necesidad de información sino como una necesidad de pensar. El segundo criterio es aprender a pensar por sí mismo.

Podemos recordar aquí que Sócrates llamaba a su método "mayéutica" que quiere decir arte de ayudar a dar a luz, -porque su madre era partera, él dice que lo heredó de ella- lo que significaba que trataba, por medio de la ironía, de hacer que el otro llevara sus opiniones (cualesquiera que fueran) hasta sus últimas consecuencias y descubriera por si mismo que eran falsas. Promover, pues, el pensamiento.

Platón en esto es supremamente crítico; llega a decir en El Banquete que el conocimiento no se transmite de un hombre a otro como se transmite el agua de una copa a otra por medio de una mecha de lana, sino que es necesario que cada cual encuentre el saber por su proceso y pueda dar cuenta de lo que sabe por haber hecho él el proceso. Es decir, lo piense por sí mismo como sus conclusiones a partir de sus propias premisas. 
Evidentemente, en una línea de pensamiento sobre la educación como la que se desprende de esa gran tradición, hay que reconocer muchas cosas. Allí no se tiene en cuenta, por ejemplo, cuánto tiempo se vaya a demorar. Platón mismo lo dice en el Teeteto que los filós ofos son libres porque a diferencia de los esclavos, como los jueces, los reyes y los abogados (por ejemplo, diríamos ahora), no tienen un plazo para concluir, en tal momento usted tiene que dame esta solución, decirme ya qué decidió, sino que se pueden tomar el tiempo que se tome un problema en su solución. Y tampoco, diríamos nosotros, tiene plazo alguno para graduar-se, nadie se graduó por lo demás como filósofo en Grecia y ni siquiera creo que ningún filós ofo griego haya sacado un tres en filosofía porque no había de eso, ellos lo que sabían era pensar que es otro problema.

Una línea de pensamiento sobre la educación, en esta dirección, contrasta por supuesto muchísimo con la realidad efectiva de la educación como empresa de calificación de fuerza de trabajo para un mercado de fuerza de trabajo calificado con un costo determinado. En la medida en que esa otra realidad ponga sus exigencias, entonces se tenderá a una posición completamente opuesta a la posición que les he resumido tan lacónicamente de Platón, según la cual es el pensamiento el que se desarrolla, con su propio ritmo. ¿Cuánto demora en descomponerse una estructura de opiniones, un sistema ideológico, para que se pueda sobre sus ruinas configurar una mentalidad científica?. No lo sabemos de antemano; en ese caso, pensamos, se tratará de formar un pensador, un investigador, un creador.

Ahora, si estamos en la otra situación y dejamos que su lógica opere sola, la lógica para la producción de una fuerza de trabajo calificada, digámoslo francamente, para la producción de una mercancía -la fuerza de trabajo es una mercancía y su calificación es un aporte de valor a una mercancía, luego es una producción de mercancía, en términos marxistas simples-des de luego que deberá quedar sometida a la lógica de la producción de mercancías; mínimo de tiempo, mínimo de costos, máximo de utilidades; entonces se desarrollará acelerando no la formación, -para eso no hay tiempo-sino la información, el entrenamiento, los conocimientos que serán requeridos en un mercado de trabajo en el cual la división del trabajo es cada vez más especializada y más restringido el campo en que efectivamente irá a operar. Pero también en esa forma, confesemos que será mínimo de tiempo, mínimo de costos, máximo de tontería. Digámoslo claramente. Es la lógica de una demanda de trabajo calificado en cualquier rama... la demanda de un entrenamiento, es decir, el trabajo tiende a ser parcial, en un punto en que no necesita conocer ni el sentido ni el funcionamiento y su lógica de un conjunto vas to sino tan solo saber operar en un sector restringido; requiere un grado de información y un mínimo de iniciativa, porque cuanto más se es pecializa el trabajo menores son las iniciativas particulares. Es decir, lo que Marx describía como características del trabajo en su estudio sobre la técnica capitalista, en El Capital, es una característica que él refería al trabajo básicamente que nosotros Ilamamos manual, pero que se tiende a extender a un conjunto cada vez más amplio del trabajo. Una de esas consideraciones de Marx, más inquietantes, es que en el proceso de desarrollo capitalista, el trabajo pierde la inteligencia del proceso, es 
decir, ya no sabe qué está haciendo. Sabe cómo debe hacerlo, pero ya no sabe qué está haciendo. Por ejemplo, se puede trabajar en una fábrica de automóviles sin tener una idea de cómo se hace un automóvil, porque se des empeña una labor parcial; pero el trabajo calificado va siendo también sometido progresivamente a la lógica de la parcialización, entonces, los requerimientos de iniciativa, de capacidad de pensar, de criticar por sí mismo, van más bien disminuyendo, en cambio las exigencias de menos tiempo y más información se van incrementando de tal manera que todo lo que nosotros llamarnos sistemas revolucionarios en la educación no se refieren a la posibilidad de formar mejor a la gente sino de informarla más rápidamente. Los sistemas audiovisuales, de lectura, sistemas de toda índole, modernos que llamamos, son sistemas de aceleración en la información: la adquisición de una mayor cantidad de datos y su manipulación en una menor cantidad de tiem po, lo que no implica ninguna posibilidad de incremento en la iniciativa, en la creatividad, en la capacidad crítica.

Nos encontramos, pues, ante esa contradicción. De todas maneras, la larga tradición racionalista en esa línea que viene desde Descartes has ta Marx o Freud, impregna nuestra cultura, sigue manteniendo la exigencia propuesta de que la educación no sea simplemente entrenamiento para una función parcial sino formación de la capacidad, capacitación en el sentido efectivo. Nos encontrarnos, pues, ante una contradición que es real: hoy en día se puede ya, en cierto modo, formar un ingeniero en una rama particular, con determinadas fómulas, de una manera eficaz, que sea casi un analfabeta en otros campos. Es decir, que su capacidad de reflexión en otros campos, el político, el literario, el humano, de reflexión sobre el amor, sobre la muerte, etc., sea prácticamente nula pero sea un Ph.D. en alas de aviones. Ph.D. que es altamente manipulable y en el sentido tradicional, por ejemplo, de la formación liberal, no es propiamente la formación de lo que los liberales Ilamaban un ciudadano. Es decir, un hombre que pueda intervenir de alguna manera, presionar concientemente en el destino de la sociedad en que vive. En realidad, el tipo de pers ona que se forma es una tuerca que debe ajustar en algún tornillo, un tornillo que puede ajustar en alguna tuerca y que debe ajustar muy bien. Es lo que llamamos un trabajador eficiente.

Esta línea de defomación puede llevarse al extremo de hacer colaborar cuarenta premios Nobel en la guerra de Vietnam sin ningún juicio sobre el sentido general de ese proyecto, sino mínimo de costos en el bombardeo, máximo de atrocidades, máximo de enfoque, con todo el aparato de la matemática puesto.

Pero nosotros no podemos elegir entre el robot y el filósofo socrático; no estamos en esa situación de una simple elección, seria ponemos por fuera de la historia. Les quiero hacer seguir dos líneas que se encuentran de una manera muy polarizada, para mostrar la tensión interna que hay en nuestras prácticas y en nuestras vivencias educativas: nuestra exigencia de la formación, de la capacitación, de un hombre, un ciudadano, un hombre capaz de juzgar, de pensar su sociedad, su situación, de tomar alguna decisión sobre su destino, es decir, un hombre que tenga algún grado de libertad y el entrenamiento de un experto sin 
ninguna capacitación efectiva. Las dos tendencias están en lo que se ha dado en llamar el problema educativo.

Les decía que íbamos a hablar de la Educación y la Filosofía. Quiero hacer antes una aclaración. No pienso hablar de la Filosofía en el sentido en que nosotros la hemos arrinconado, como una materia al lado de las otras materias, corno solemos decir, sino en el sentido de una educación filosófica.

Una educación filosófica podríamos calificarla -claro que el contexto es muy amplio y puede ligarse a una deteminada posición actual- como una educación racionalista, dejando abiertos varios tipos de racionalismo. Los criterios mínimos del racionalismo nos los da Kant. Son tres las exigencias racionales, según Kant, probablemente el maestro del racionalismo modemo, tanto el de Marx como el de Freud: la una pensar por sí mismo, es decir, el criterio de no tener una mentalidad pasiva que recibe sus verdades y simplemente las acepta de alguna autoridad, de alguna tradición, de algún prejuicio; el segundo, ser capaz de ponerse en el punto de vista del otro, es decir, no mantener dogmáticamente el propio punto de vista como el único y ser capaz de entrar en el diálogo con los otros puntos de vista, en la perspectiva de llevar cada cual hasta sus últimas consecuencias sus puntos de vista, a ver en qué medida son coherentes consigo mismos; y el tercero, es llevar las verdades ya conquistadas, hasta sus últimas consecuencias, es decir, el criterio de lo que llama Kant la razón, tomar cualquier verdad como un modelo para encontrar otra, una verdad matemática o cualquier otra. Esos criterios racionalistas son criterios que se piensan en la dirección de la formación.

Ahora, hablando de una Educación filosófica como una posición en esas dos tendencias que primero traté de señalar y que son muy polarizadas, ¿qué significa allí una educación filosófica?...

Significa poner el acento en la primera tendencia, en la fomación. Eso significa que todo lo que nosotros llamamos materias, tiende, por lo menos, a darse en forma filosófica. Es decir, como pensamiento y no como conjunto de información.

Ahora bien, cualquier materia se puede dar, en principio, en forma filosófica. Cualquiera. Por ahora, no nos interesa de qué materia se trate. Pero puede darse en forma perfectamente antifilosófica o, como decía Marx, aconceptual, es decir, sin que incluya pensamiento propiamente dicho.

Podemos considerar una materia. La Geografía. ¿Qué puede significar una Geografía Filosófica?.

Efectivamente, una geografía filosófica sería una geografía que tuviera: primero, principios explicativos, es decir, cuál es el peso de las diferentes condiciones geográficas, climatéricas, orográficas y demás, en la vida humana en deteminado período histórico. Podría considerar, por ejemplo, en la descripción de un país, no solamente que hay montañas en tal sitio o en tales sitios, ni que miden tanto de alto y tienen tal clima y pluviosidad, sino cómo ese hecho se impone como un 
sentido y un condicionamiento de la vida humana, por ejemplo, por qué en las zonas montaños as hay una forma de vida diferente, teniendo que vincularse con la historia; por qué en las montañas nuestras, por ejemplo, no es tan importante una aristocracia terrateniente y hay más propiedad campesina pequeña y por tanto hay una vida, por una parte, mas conservadora, las montañas son neveras donde se guardan los refranes, las formas lingüísticas, las formas del pasado; pero, por otra parte, son más independientes, también son refugios de hombres libres y finalmente de guerrilleros y mucha gente así. ¿Por qué la historia se desarrolla más lentamente en las montañas y más rápidamente en las llanuras y a lo largo de los ríos y en las costas, a donde llegan las influencias de otros país es, donde el transporte pone más directamente en contacto a la gente?. Es decir, qué es una montaña como condición de existencia, yal mismo tiem po qué es un desierto, por qué produce gobernantes, nómadas, por qué produce un arte distinto lleno de arabescos sin líneas de medida, de distinción de propiedades, sin arcos, sueltos: ¿qué quiere decir todo esto? ¿qué tipo de mentalidad, de concepción del mundo tienen?

Y todo lo que llamamos Geografía Humana también significa, y su significación está en relación con un período, porque cambia según, por ejemplo, el avance o retroceso de las fuerzas productivas. As í, con determinado grado de tecnificación, ser habitante de una isla significa ser aislado, pero

con otro grado de comunicación; significa estar comunicado con todo el mundo, como era la marina inglesa; puede estar protegido contra la invasión alemana pero en una guerra actual ya no estaría protegida de nada. Es decir, la significación geográfica cambia cuando cambian los modos, las técnicas y las relaciones de producción.

Hacer una geografía filosófica quiere decir hacerla explicativa pero también vital; no mitologizarla; por ejemplo, no quién fundó tal ciudad, sino en qué sitio había condiciones para poderla fundar, porque las ciudades no se decretan; si no están los chibchas, la sal de Zipaquirá, la protección contra los piratas, no se funda la capital aunque la decreten. Porque decretaron muchas, la primera fue Santa María La Antigua del Darién, y la decreté nada menos que Colón y ahí ahora no hay nada, eso depende es de dónde, no de quién la fundó. Es decir, enseñar la geografía es darle un sentido y es lo que quiere decir enseñar filosóficamente. Y así todo. Evidentemente, la historia no es el recuento de acontecimientos de lo que ocurrió en el pasado, sino la manera cómo el mundo se concibe, cómo se muere y cómo se ama en cada época, según las condiciones de vida, la manera como naturalmente se produce, se cambia y lo que se es y los hombres que todo eso producen y qué produce en ellos la historia. La historia filosófica es también más próxima a nosotros, pero todas las materias se pueden hacer filosofía.

Educación y filosofía no quiere decir dejarle más horas a una materia aburridora en la que se cuentan muy sumariamente ciertas historiecitas de la filosofía: que a Heráclito le gustaba bañarse siempre en distintos ríos... que Sócrates no sabía nada... que Platón tenía no se qué idea sobre el cielo... y cosas así que como 
tantas otras se "desembuchan' en el examen final y sale uno de todo esa indigestión como por un inmenso vómito y no se vuelve a acordar de nada.

A todos nosotros nos ha pasado con una u otra materia; en sí mismas pierden interés, se termina por saber de botánica no se qué cuestiones en latín, no se sabe por qué, que las cucurbitáceas... que las solanáceas... y finalmente no se recuerda nada más. Para explicar la vida se tuvo el cuidado de emplear el tablero pero rió el pensamiento, esto es muy frecuente en la educación y mientras más audiovisual más se acentúa: aquí está la célula que se va engordando, engordando... y se va ahorcando y una se parte en dos -y entonces ya estamos aprendiendo histología- vamos a ver la partenogenia...

Pero, ¿qué es una membrana? ¿es la línea que he pintado? No, es decir, aprender a ver el misterio de la cosa, qué es esto que llamamos membrana que al mismo tiempo protege del mundo y comunica, que sirve para aislarse y para relacionarse, para dejar pasar lo que combina con lo interior y expulsar lo que no combina, y al mismo tiempo para que todo el estruendo del mundo no desbarate el pequeño núcleo; ¿qué es ese mis terio que llamamos membrana y que luego será el cerebro? ¿Qué significa vida, cómo una misma cosa es al mismo tiempo una memoria que vuelve a darse y contiene en alguna forma el secreto, la clave de su reproducción, siendo al mismo tiempo una Cosa y una memoria?. ¿Cómo crear la incógnita en lugar de dar la apariencia de resultados impensados? ¿Cómo hacer, pues, una Biología pensable?, porque así no se olvida lo que se convierte en instrumento nuestro, lo que nos ayuda luego a ver el mundo distinto, a nosotros mismos distintos, y a pensar. Eso no se nos olvida, como no se nos olvida el idioma en que hablamos. Lo que se nos olvida es lo que no podemos convenir en instrumento nuestro; nuestro psiquismo tiene una capacidad de eliminar lo que no puede as imilar, bastante buena por otra parte, pues ¿qué haríamos con todo ese conjunto de cosas que no podemos utilizar en nada? No deja de ser un acto razonable y saludable el acto del olvido, que vuelve a pemitir aprender otras cosas y que no nos mantiene atiborrados de datos inutilizables, como todas esasfechas históricas en que el uno murió, el otro nació y el otro lo conoció, y que no sabemos qué significa; y de todos esos nombres botánicos y esas clasificaciones que no nos enseñaron a pensar las plantas, a verlas con una lógica con la que antes no las veíamos.

Lo único que quería hoy decilles, con esta charla, es que en la medida en que nosotros queramos que la educación signifique algo más que entrenamiento de un experto para un mercado que lo demanda -es una función específica- y que todo tienda a la formación de un ciudadano -para decidirlo en témino antiguo, griego: la revolución plantea lo económico- en esa medida deberíamos acentuar la educación filosófica. Hay muchas cosas que no podemos evitar, un ritmo, un pensum, pero sí hay una cosa que podemos mejorar, pensar nosotros mismos lo que Ilamamos nuestras materias, inquietar-las y transmitirles entusiasmo. Eso es lo que menos se transmite. 
La educación comienza con una noción que ya es una división terrible del trabajo; ya en la escuela primaria aprendemos que hay dos cosas: una aburrida y útil, la clase; y otra inútil y maravillosa, el recreo. Pronto se nos ubica muy bien el tiempo y el sitio: en la clase uno se aburre, pero es necesario, se aprende, si no se pierde el año; en cambio, en el recreo uno goza, pero eso no sirve para nada; y algo se queda para siem pre en nuestra mentalidad. Leer, claro, se lee el Quijote, a los estudiantes se lo recomiendan, se lo recomienda el profesor de Preceptiva Literaria y le enseña que el gerundio está muy bien usado por Cervantes y lo asocia con Gramática, una de las cosas más aburridoras, pero se lo recomiendan en el orden del deber y como el Quijote lo que es, es una broma superior, y no vuelve a encontrar el espíritu de seriedad que es taba buscando, ni lo estudia -porque no se deja, si no se goza se cierra-, ni tampoco lo disfruta, porque el disfrute es el recreo, o la parranda, el saber no es disfrute y esa pequeña separación se nos mantiene durante toda la vida: aprender es lo contrario de disfrutar, disfrutar es lo contrario de aprender, pero entonces no habrá más que un interés exterior.

Todo el mecanismo de la educación tendrá que bajarse, no habrá transmisión que el profesor pueda hacer de una pasión que él tiene por un tema, sino en el mecanismo de la nota o el de la competencia; hay otros a los que les puedo ganar y que me pueden ganar, hay una promoción de clase a clase y luego, durante la vida del sector social a sector social, de carros ('voy a pasar del Renault 4 Renault 6") y le jalo duro a la fábrica, o a la oficina o a lo que tenga, así se promueve, pero no en la búsqueda de la cosa misma de saber eso que se nos ha hecho necesario, inquietante, interesante, en la solución de una incógnita que nos conmueve, sino la nota, la promoción, la competencia, aquí compito con éste, y ya no es simplemente el miedo de perder el año y ser regañado o penado o perder algo, entonces es la competencia: si avanzo más le gano a éste, es decir, el mecanismo competitivo en el cual el fracaso de uno es el éxito del otro, porque fracasó menos que él, y se convierte en equivalente el éxito del uno y el fracaso del otro.

Y entonces se ve, se lanzan en la pista de las diversas carreras, a correr en la competencia a ver cuál sale adelante como profesional destacado; ¿en qué carrera corre usted?... jen la de medicina!... ¡A! ...".

Debemos confesar que nosotros estamos situados en una circunstancia objetiva que no podemos transfomar desde el aula. Es un reconocimiento simplemente realista; no se puede revolucionar el aparato productivo de fuerzas de trabajo calificado desde un aula, eso hay que reconocerlo tranquilamente. No podemos tomar socráticamente a un alumno por medio de preguntas hasta que él mismo descubra -como hacía Sócrates con el esclavo- la geometría por su propio pensamiento.

Pero debemos considerar tam bién esto: que de todos modos sería ideal, de todos modos la formación debería ser la meta de todo el que considere el asunto como algo más que la producción de un experto adecuado a una demanda de trabajo calificado. 
Esa es la única forma de luchar por una democracia, como ustedes la quieran considerar: limitada -capitalis ta- o ampliada -socialista-, pero de todas maneras, la única forma de lucha por una democracia es acentuar la educación filosófica, por lo menos la única forma de lucha dentro del trabajo educativo; claro que hay muchas otras: sindical, etc., pero digo: dentro de ese trabajo, la única forma de búsqueda de una democracia, de ampliación de una democracia, es la colaboración para que se pueda aprender allí, por lo menos parcialmente, o por lo menos inquietarse en pensar; es decir, promover una educación filosófica y no una información cuantificada, masiva, separada, beatificada, que puede servir para trabajar, pero que, para vivir, no tiene más utilidad que la que de ella se pueda derivar un ingreso mayor que el que se tendría sin ella. Es decir, la capacitación impone una tendencia, es difícil, pero es posible, por lo menos, dirigirse en ese sentido. Sería idealista, evidentemente, pensar que se puede con es to cambiar el aparato educativo; nosotros no podemos; podemos imaginarlo, pero no podemos llevar a efecto nuevas combinaciones del trabajo productivo y el estudio, fuera de las que da una determinada sociedad en que estamos; no vamos a cambiar la división social del trabajo en un aula, eso también es perfectamente cierto, porque allí no está determinándose la división social del trabajo y allí no se puede cambiar.

Pero sí podemos, allí, hacer una lucha restringida pero muy interesante y que podría ser apasionante, por la democracia, en el sentido de que un hombre que pueda trizcar, pensar por sí mismo, apasionarse por el sentido, la investigación, es un hombre mucho menos manipulable que el experto de que hablamos.

Ese es un aporte que podría provenir de una intensificación, en nosotros mismos como educadores, de la tendencia que les he planteado en esta charla, a la educación filosófica. Lo que quería decir, pues, con Educación y Filosofía, era promover la educación filosófica. 